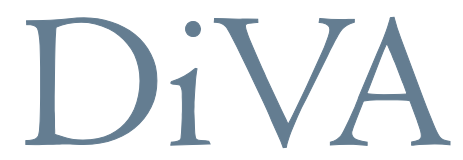

http://uu.diva-portal.org

This is an author produced version of a paper presented at the Twenty Seventh Annual International Pittsburgh Coal Conference, October 11-14, 2010, Pittsburgh, USA. This paper has been peer-reviewed but may not include the final publisher proof-corrections or pagination.

Citation for the published paper:

Höök, Mikael

"Future coal production outlooks in the IPCC Emission Scenarios: Are they plausible?"

Twenty Seventh Annual International Pittsburgh Coal Conference URL: http://www.engineering.pitt.edu/Coal Conference/Proceedings.aspx

Access to the published version may require subscription. 


\title{
Future coal production outlooks in the IPCC Emission Scenarios: Are they plausible?
}

\author{
Mikael Höök* \\ Contact e-mail: Mikael.Hook@fysast.uu.se \\ * Uppsala University, Global Energy Systems, Department of physics and astronomy, Box 535, SE-751 \\ 21, Uppsala, Sweden, webpage: http://www.fysast.uu.se/ges/
}

\begin{abstract}
:
Anthropogenic climate change caused by $\mathrm{CO}_{2}$ emissions is strongly and fundamentally linked to the future energy production. The Special Report on Emission Scenarios (SRES) from 2000 contains 40 scenarios for future fossil fuel production and is used by the IPCC to assess future climate change. Coal, with its $26 \%$ share of world energy, is a major source of greenhouse gas emissions and commonly seen as a key contributor to anthropogenic climate change. SRES contains a wide array of different coal production outlooks, ranging from a complete coal phase-out by 2100 to a roughly tenfold increase from present world production levels. Scenarios with high levels of global warming also have high expectations on future fossil fuel production.

The assumptions on resource availability are in SRES based on Rogner's assessment of world hydrocarbon resources from 1997, where it is stated that "the sheer size of the fossil resource base makes fossil sources an energy supply option for many centuries to come". Regarding the future coal production it is simply assumed to be dependent on economics, accessibility, and environmental acceptance. It is also generally assumed that coal is abundant, and will thus take a dominating part in the future energy system. Depletion, geographical location and geological parameters are not given much influence in the scenario storylines.

This study quantifies what the coal production projection in SRES would imply in reality. SRES is riddled with future production projections that would put unreasonable expectation on just a few countries or regions. Is it reasonable to expect that China, among the world's largest coal reserve and resource holder and producer, would increase their production by a factor of 8 over the next 90 years, as implied by certain scenarios? Can massive increases in global coal output really be justified from historical trends or will reality rule out some production outlooks as implausible?

The fundamental assumptions regarding future fossil fuel production in SRES was investigated and compared with scientific methodology regarding reasonable future production trajectories. Historical data from the past 20 years was used to test how well the production scenarios agree with actual reality. Some of the scenarios turned out to mismatch with reality, and should be ruled out. Given the importance of coal utilization as a source of anthropogenic GHG emissions it is necessary to use realistic production trajectories that incorporate geological and physical data as well as socioeconomic parameters. SRES is underpinned by a paradigm of perpetual growth and technological optimism as well as old and outdated estimates regarding the availability of fossil energy. This has resulted in overoptimistic production outlooks.
\end{abstract}

Key words: Emission scenarios, $\mathrm{CO}_{2}$ emissions, future coal production, peak coal 


\section{Introduction}

The world's primary energy supply is dominated by fossil energy and over $80 \%$ is derived from combustion of oil, gas and coal (IEA, 2009). Oil accounts for 34\%, coal for $27 \%$ and natural gas for $21 \%$ (IEA, 2009). The use of fossil fuels is also the dominating source of anthropogenic greenhouse gasses (GHG), particularly carbon dioxide. In 2007, nearly 29 billion tons of $\mathrm{CO}_{2}$ were emitted due to fossil fuel consumption (IEA, 2009). Around 57\% of all global anthropogenic GHGs derive from fossil fuel combustion, with energy supply as the largest contributing sector (Figure 1). Consequently, anthropogenic climate change caused by GHG emissions is strongly and fundamentally linked to future energy production. Studies of the future energy use and production are vital for understanding future GHG emissions.

Among the fossil fuels, coal is the most carbon intensive fuel and causes the largest GHG emissions per energy unit produced. The use of coal is also the most criticised part of the fossil energy sector. Consequently, it is important to inspect what kind of expected coal usage and corresponding emissions that is reasonable in the future.

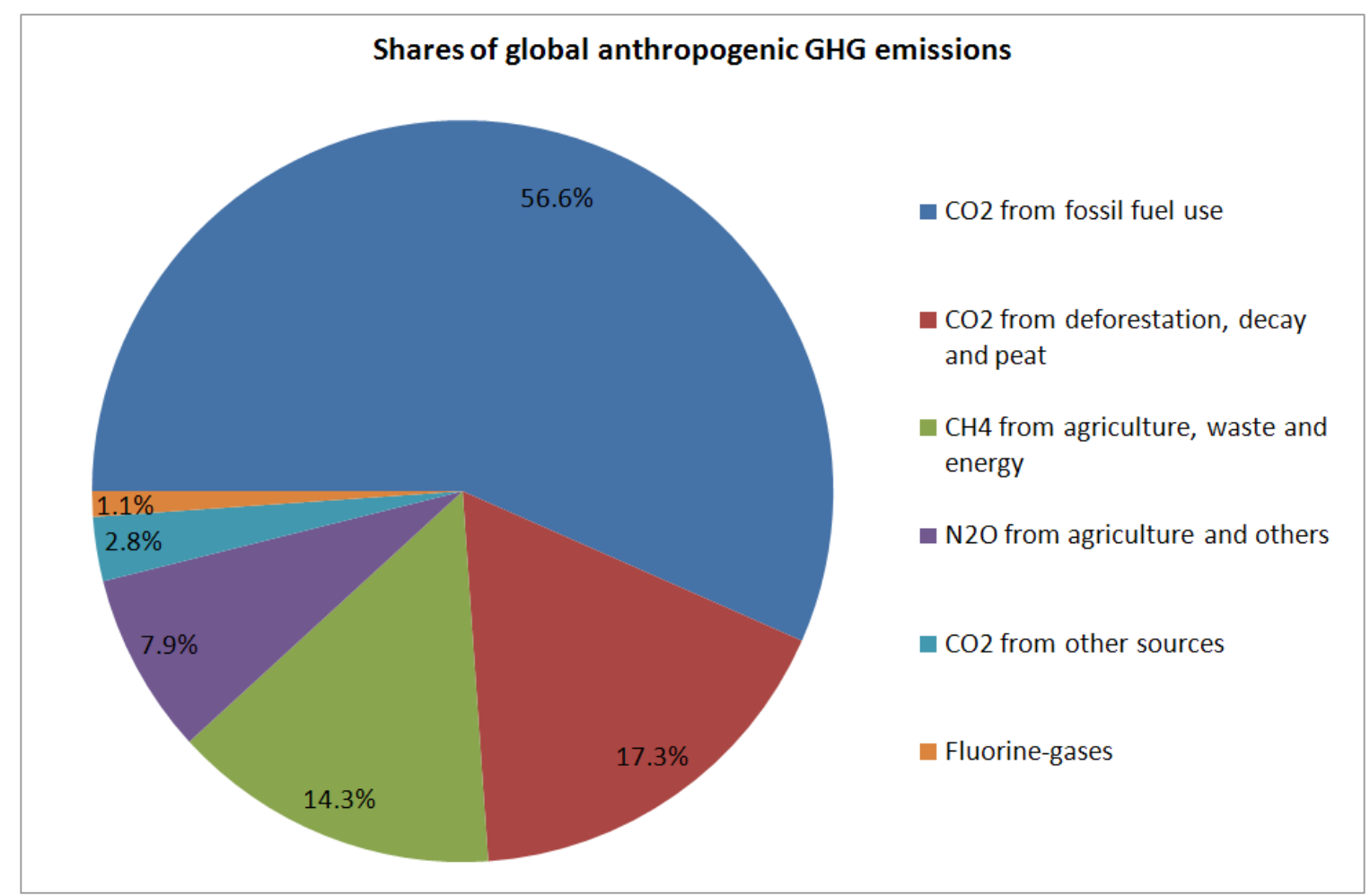

Figure 1: Shares of total GHG emissions. CO2 from fossil fuel use is dominating in terms of emissions. This strongly links energy production to GHG emissions and ultimately anthropogenic climate change to assumptions about future fossil fuel production. Derived from: IPCC (2007) 


\subsection{Aim of this study}

Coal is a major source of GHG emissions and an integral part of the world's energy system for the foreseeable future. The IPCC emission scenarios (SRES, 2000) contain a number of outlooks for future coal production. This study aims to investigate those production outlooks and their feasibility, and the paper is mainly reflecting previous studies on coal and the fossil fuel use in the IPCC emission scenarios (Höök et al., 2010a; Höök et al., 2010b).

This study will not venture into any form of climate change effects or spend any time reviewing or commenting the issue of man-made climate change. Such studies have already been made by others (Kharecha and Hansen, 2008; Brecha, 2008; Nel and Cooper, 2009). Instead, the focus will be strictly placed on the plausibility of future coal production trajectories. However, if assumptions regarding the most dominating source of GHG are shown to be flawed it will naturally have repercussions on the validity of the climate change projections derived from models using those emission scenarios as input. The fundamental guiding principle in modelling - garbage in, garbage out - should always be held dear.

\section{Background to SRES}

The World Meteorological Organization (WMO) and the United Nations Environment Program (UNEP) established the Intergovernmental Panel on Climate Change (IPCC) in 1988. Its task is to assess scientific, technical and socio-economic information relevant for understanding anthropogenic climate change. The results have been published in several assessment reports and some special reports over the years (IPCC 1990; 1995; 2001; 2007). The IPCC has been using a set of scenarios, describing future development of society and emissions, to assess future climate change. The first set was published in 1990, followed by subsequent sets in 1992 and 2000. Titles, methods, classifications, assumptions have all changed over time and this has been reviewed by Girod et al (2009).

All of the scenarios from 1992 where found to exaggerate one or more current climate and economic trends, leading to correspondingly exaggerated atmospheric greenhouse gas concentrations (Gray, 1998). Revisions were obviously needed and work was undertaken to develop new scenarios. The current scenario set is called the Special Report on Emission Scenarios (SRES) and were published in 2000. It is the basis for the majority of all long-term climate change projections, including those of the Fourth Assessment Report (IPCC, 2007).

SRES is built on 40 different scenarios and evaluations of the associated GHG emissions. The scenarios are based on literature reviews, development of narrative storylines and the quantification of these story lines with the help of six integrated models from different countries. SRES illustrates that the future emissions, even in the absence of explicit environmental policies, very much depend on the choices that people make, how economies are structured, which energy sources that are preferred and how people use available land resources. IPCC state that "they represent pertinent, plausible, alternative futures" and derive from a descriptive and open-ended methodology that aims to explore alternative futures (SRES, 2000). The emissions scenarios are later used as an input to various climate models to depict how the climate may change under various assumptions of future anthropogenic emissions.

The emission scenarios are neither claimed to be predictions nor forecasts, even though they are commonly used as such. Additionally, no probabilities or likelihoods are assigned to any of the scenarios. All scenarios are equally sound and valid, which was required by the Terms of Reference (SRES, 2000). The equal probability of each emission scenario has been described as a rather peculiar assumption (Höök et al., 2010a). In any event, this cannot be the case, since the 
range is due to a combination of component ranges of uncertainty, and thus the extremes of this range must be less probable than the central estimate (Jones, 2001). The IPCC emission scenarios have been criticized for its inability to assign probabilities to the projections (Schneider, 2001; 2002). Additional discussion on the communicative issues and uncertainties within SRES can be found in Schenk and Lensink (2007).

Fossil fuel combustion, the main source of anthropogenic GHG emissions, as well as future production, can be modelled by probabilistic methods (Kontorovich, 2009). This makes claims of equal probability for both high and low resource/production scenarios appear questionable. "Equally valid scenarios" rather materializes as an attempt to assign unjustifiably high weight to more extreme visions compared to reasonable outlooks.

\subsection{Scenario overviews}

Each of the participating modelling teams behind the emission scenarios used computer models and experience considering long-range development of economic, technological and environmental systems to generate quantifications of the storylines, which develop the different scenarios. To simplify the procedure of depicting alternative future developments, each of the four scenario families is described by a specific storyline. The writing teams formulated the storylines in a process that identified driving forces, key uncertainties, possible scenario families and their logic (Höök et al., 2010a). Within each scenario family different variations of global and regional development and their implications for global greenhouse gas emission are explored. There is no business-as-usual scenario or disaster scenario and it was also decided that possible surprises, such as a new world war or major depression, should not be considered. This has been described as a built-in linear logic and utopian thought (Hjerpe and Linnér, 2008).

The SRES storyline titles have been kept simple: A1, A2, B1 and B2. They can be shown very straightforwardly in a two-dimensional tree, which shows the global-regional focus and the economic-environmental orientation (Figure 2). Closer description of the scenario families can be found in SRES (2000). The four storylines and scenario families describe future worlds that are wealthier compared to the current world. It is important to notice that they do not include additional climate initiatives such as policies to limit GHG gases or to adapt to the expected climate change. Each scenario has a number of driving forces, such as population, economy, technology, energy, land-use, and agriculture. Different preferences and priorities lead to a huge variety of corresponding GHG emissions.

The A1 storyline and scenario family describes a future world of very rapid economic growth, low population growth and the rapid implementation of new and more efficient technologies. The key plots are convergence among regions, capacity building, and increased cultural and social interactions with a significant reduction in the difference in per capita income. The A1 family is the largest and branches out in several subfamilies, each exploring an alternative future with different preferences.

The A2 family contains visions of a very heterogeneous world. The key scheme is selfreliance and preservation of local identities and cultures. Fertility patterns across the globe converge very slowly, which results in high population growth. Economic development is primarily focused on regional growth and per capita economic growth and technology change is more fragmented and slower than in other scenario families.

The B1 scenario family describes a convergent world with the same low population as in the A1 storyline, but with rapid changes in economic structures toward a service and information economy, with reductions in material intensity, and the implementation of clean and resource- 
efficient technologies. The emphasis is on global solutions to economic, social and environmental sustainability, including improved equity, but without additional climate initiatives.

Finally, the B2 scenario family describes a world in which the emphasis is on local solutions to economic, social and environmental sustainability. It results in a world with moderate population growth, intermediate economic growth and less and more diverse technological change than in the B1 and A1 storylines. B2 is oriented toward environmental protection and social equity, but also focuses on local and regional initiatives.

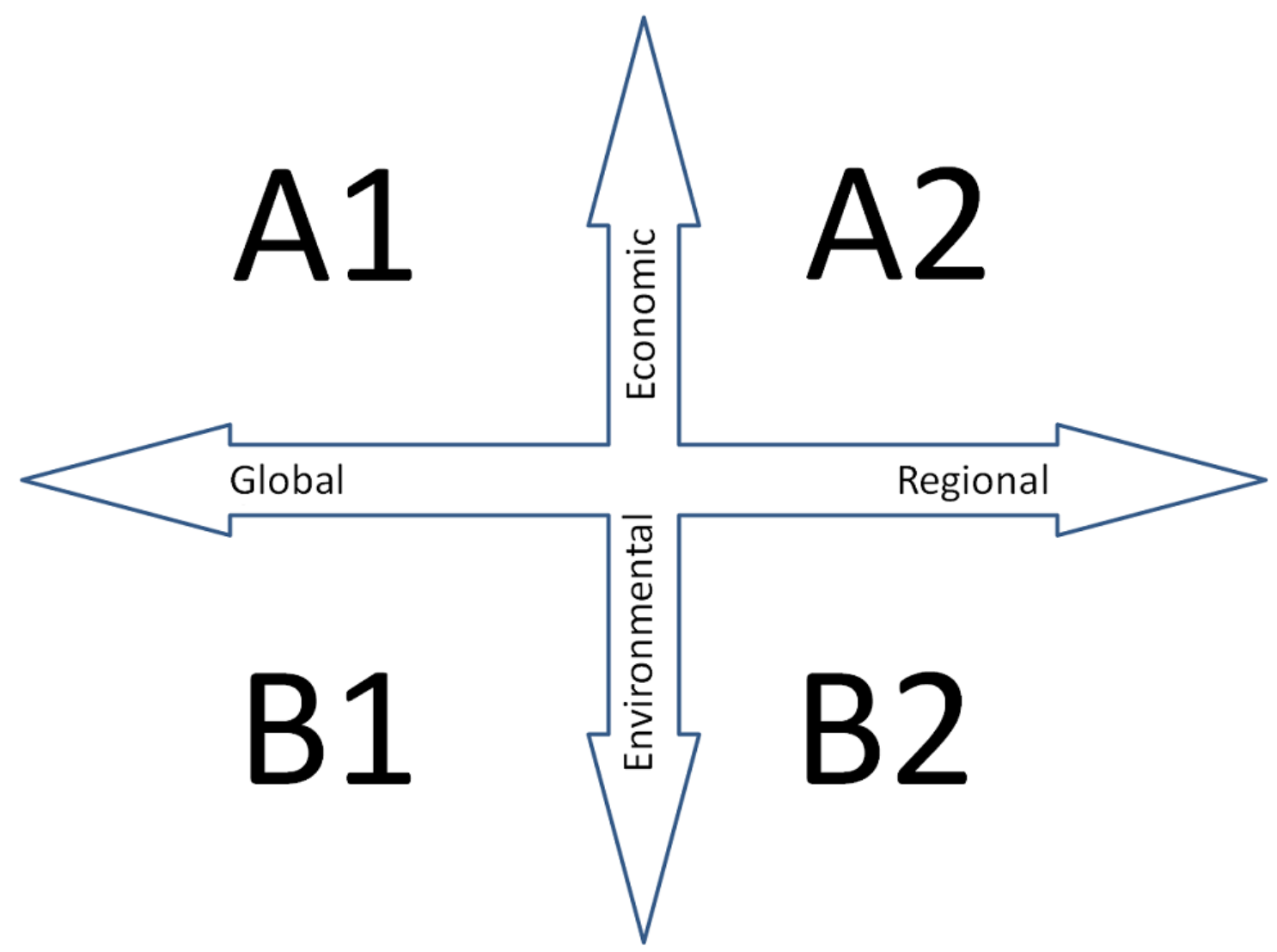

Figure 2. Schematic illustration of the SRES scenarios. The four scenario families are shown, very simplistically, as branches of a two-dimensional tree. Each scenario is based on a common specification of the main driving forces such as population, economy, technology, energy, landuse and agriculture. Adapted from SRES (2000)

All qualitative and quantitative properties of scenarios belonging to the same family were set to match the corresponding features of the underlying storyline. Together, 26 scenarios were harmonized to have the same assumptions about global population and GDP development. The remaining 14 scenarios explore alternative interpretations of the four scenario storylines, such as different rates of economic growth and variations of population growth (Sivertsson, 2004; SRES, 2000). The main characteristics of the scenarios are presented in Table 1. 
Table 1. Main characteristics of development in different scenario families and groups, as applied to harmonized scenarios. Adapted from SRES (2000)

\begin{tabular}{|c|c|c|c|c|c|c|c|}
\hline Family & \multicolumn{4}{|c|}{ A1 } & A2 & B1 & B2 \\
\hline Subgroup & $A 1 C$ & $A 1 G$ & $A 1$ & $A 1 T$ & $A 2$ & B1 & $B 2$ \\
\hline $\begin{array}{l}\text { Population } \\
\text { growth }\end{array}$ & Low & Low & Low & Low & High & Low & Medium \\
\hline GDP growth & Very high & Very high & $\begin{array}{l}\text { Very } \\
\text { high }\end{array}$ & Very high & Medium & High & Medium \\
\hline Energy use & Very high & Very high & $\begin{array}{l}\text { Very } \\
\text { high }\end{array}$ & High & High & Low & Medium \\
\hline $\begin{array}{l}\text { Land-use } \\
\text { changes }\end{array}$ & $\begin{array}{l}\text { Low- } \\
\text { medium }\end{array}$ & $\begin{array}{l}\text { Low- } \\
\text { medium }\end{array}$ & Low & Low & $\begin{array}{l}\text { Medium- } \\
\text { high }\end{array}$ & High & Medium \\
\hline $\begin{array}{l}\text { Resource } \\
\text { availability }\end{array}$ & High & High & Medium & Medium & Low & Low & Medium \\
\hline $\begin{array}{l}\text { Technological } \\
\text { development }\end{array}$ & Rapid & Rapid & Rapid & Rapid & Slow & Medium & Medium \\
\hline $\begin{array}{l}\text { Change } \\
\text { favouring }\end{array}$ & Coal & Oil \& Gas & Balanced & $\begin{array}{l}\text { Non- } \\
\text { fossils }\end{array}$ & Regional & Efficiency & $\begin{array}{l}\text { "Dynamics } \\
\text { as usual" }\end{array}$ \\
\hline
\end{tabular}

\section{Future coal supply in SRES}

Resource availability in SRES (2000) is built around the works of Rogner (1997) and Gregory and Rogner (1998), and relies on them for detailed discussion of the estimated hydrocarbon amounts. Closer discussion on fossil fuel availability can be found in SRES (2000) and Sivertsson (2004). The message of Rogner (1997) is that the vast unconventional hydrocarbon occurrences and historically observed rates of technology change would allow hundreds of years with availability of fossil energy with low long-term costs, i.e. not significantly higher than the market price of the 1990s. Rogner (1997) also states that additional occurrences beyond the common resource base makes fossil fuels appear as an almost unlimited energy source. In summary, main point of Rogner (1997) is that "the sheer size of the fossil resource base makes fossil sources an energy supply option for many centuries to come", provided that economy and technological progress are favourable.

For coal, Rogner (1997) highlight the many fluctuations in world reserve and resource assessments. A more holistic compilation of the fluctuations can be seen in Tables 2-6 or Figure 3 . There is no discussion about the historical trends in global reserve and resource assessments in the work of Rogner (1997), in contrast to Höök et al. (2010b). Table 2 and 3 show some dramatic changes in the estimated in situ resources in the published assessments by WEC and BGR.

Rogner's overview is also very brief in comparison with oil and gas, mostly calling out to Federal German Institute of Geosciences and Natural Resources (BGR) as the main source. The total coal resource is placed at 6246 Gtoe, which would equal 8744 Gt of coal (assuming 30 GJ/ton coal). Nearly $60 \%$ of all coal is found in the most uncertain category.

Rogner (1997) places the coal reserves at 1003 Gtoe, equalling $1404 \mathrm{Gt}$ of coal (assuming $30 \mathrm{GJ} /$ ton coal). This is strikingly higher than the latest global reserve estimates of 826 Gt (WEC, 2009; BP, 2010). Even the latest estimate from the BGR (2009) only places total coal reserves at 503 Gtoe or $997 \mathrm{Gt}$. A full compilation of historical world coal reserve estimates can be seen in Tables 4 and 5. Rogner's data can only be called outdated and should be replaced with more recent studies and preferably also a discussion of the historical trends in coal supply estimates. The global coal reserves reported by World Energy Council (WEC) contain a declining trend since late 1980s (Table 4). On the other hand, the BGR data does not show this 
trend (Table 5). However, the BGR has been known to exaggerate coal reserves compared to the national agencies that provide the reports used by the WEC (Höök et al., 2010b).

Table 2. Total resource estimates in Gt for selected countries and the world as published by the WEC. Data source Höök et al. (2010b)

\begin{tabular}{cccccccccccc}
\hline $\mathbf{1 9 2 4}$ & 5398 & 996 & 79 & n.a & 166 & 56 & 423 & 19 & 190 & n.a & 7398 \\
\hline $\mathbf{1 9 2 9}$ & 3829 & 1213 & 79 & 489 & 166 & 58 & 423 & n.a & 190 & n.a & n.a \\
\hline $\mathbf{1 9 3 7}$ & 2893 & 10113 & 26 & 611 & 171 & 214 & 427 & 68 & 306 & n.a & 16025 \\
\hline $\mathbf{1 9 4 8}$ & 2897 & n.a & n.a & n.a & n.a & 90 & n.a & n.a & n.a & n.a & n.a \\
\hline $\mathbf{1 9 7 4}$ & 2925 & 1000 & 83 & 5714 & 199 & 44 & 317 & 61 & 163 & 3 & 10754 \\
\hline $\mathbf{1 9 7 6}$ & 3600 & n.a & 86 & 6948 & 372 & 93 & n.a & n.a & 190 & 3 & 11724 \\
\hline $\mathbf{1 9 8 0}$ & 1073 & 1463 & 115 & 6007 & 860 & 93 & 295 & 186 & 190 & 19 & 13476 \\
\hline $\mathbf{1 9 8 6}$ & 1570 & 2737 & 115 & 5502 & 785 & 133 & 332 & 197 & 186 & 23 & 11990 \\
\hline $\mathbf{1 9 8 9}$ & 1570 & 1094 & 245 & 5487 & 821 & 122 & 332 & 198 & 378 & 6 & 10052 \\
\hline $\mathbf{1 9 9 2}$ & 1570 & 954 & 245 & 5487 & 821 & 122 & 241 & 207 & 378 & 64 & 10236 \\
\hline $\mathbf{1 9 9 5}$ & 1216 & 954 & 286 & 5487 & 817 & 126 & 269 & 223 & 190 & 64 & 10567 \\
\hline $\mathbf{1 9 9 8}$ & 1570 & n.a & n.a & 4141 & 454 & 126 & 308 & 74 & n.a & n.a & n.a \\
\hline $\mathbf{2 0 0 0}$ & 1321 & n.a & n.a & n.a & 435 & 116 & 308 & 65 & n.a & n.a & n.a \\
\hline $\mathbf{2 0 0 4}$ & 1564 & n.a & n.a & n.a & 431 & 115 & 100 & 170 & n.a & 46 \\
\hline $\mathbf{2 0 0 7}$ & 1560 & n.a & 290 & n.a & n.a & 115 & 50 & 56 & n.a & 57 & n.a \\
\hline & & & & & & & n.a \\
\hline
\end{tabular}

Table 3. Total resource assessments in Gt as published by the BGR. Year 1980 is seen as identical to the WEC report from the same year. Data source Höök et al. (2010b)

\begin{tabular}{cccccccccccc}
\hline & USA & China & India & FSU & Australia & $\begin{array}{c}\text { South } \\
\text { Africa }\end{array}$ & Germany & Poland & UK & Indonesia & World \\
\hline $\mathbf{1 9 7 6}$ & n.a & n.a & n.a & n.a & n.a & n.a & n.a & n.a & n.a & n.a & 14185 \\
\hline $\mathbf{1 9 8 0}$ & 1073 & 1463 & 115 & 6007 & 860 & 93 & 295 & 186 & 190 & 19 & 13476 \\
\hline $\mathbf{1 9 8 8}$ & n.a & n.a & n.a & n.a & n.a & n.a & n.a & n.a & n.a & n.a & 11610 \\
\hline $\mathbf{1 9 9 3}$ & 1725 & 935 & 201 & 5493 & 861 & 155 & 380 & 194 & 447 & 42 & 10994 \\
\hline $\mathbf{1 9 9 8}$ & 1478 & 766 & 166 & 5499 & 371 & 55 & 371 & 168 & 227 & 18 & 9636 \\
\hline $\mathbf{2 0 0 1}$ & 1122 & 668 & 163 & 2217 & 194 & 5 & 264 & 144 & 190 & 24 & 5424 \\
\hline $\mathbf{2 0 0 4}$ & 1090 & 1090 & 259 & 2295 & 298 & 164 & 88 & 70 & 5 & 11 & 4668 \\
\hline $\mathbf{2 0 0 5}$ & 1058 & 1090 & 292 & 2326 & 305 & 164 & 91 & 101 & 7 & 65 & 6039 \\
\hline $\mathbf{2 0 0 6}$ & 1359 & 4367 & 252 & 2915 & 194 & 49 & 85 & 179 & 190 & 27 & 9554 \\
\hline $\mathbf{2 0 0 7}$ & 6720 & 4367 & 230 & 2931 & 148 & 29 & 83 & 179 & 187 & 24 & 15511 \\
\hline $\mathbf{2 0 0 8}$ & 8120 & 5509 & 278 & 4336 & 359 & 31 & 191 & 401 & 188 & 93 & 20767 \\
\hline
\end{tabular}


Table 4. Recoverable reserve estimates in Gt for selected countries and the world as published by the WEC. Data source Höök et al. (2010b)

\begin{tabular}{|c|c|c|c|c|c|c|c|c|c|c|c|}
\hline & USA & China & India & FSU & Australia & $\begin{array}{l}\text { South } \\
\text { Africa }\end{array}$ & Germany & Poland & UK & Indonesia & World \\
\hline 1924 & 5398 & 996 & 79 & n.a & 166 & 56 & 423 & 19 & 190 & - & 7398 \\
\hline 1929 & 3829 & 1213 & 79 & 489 & 166 & 58 & 423 & n.a & 190 & n.a & n.a \\
\hline 1937 & n.a & n.a & 5 & 309 & 9 & 8 & 109 & 15 & 130 & n.a & 691 \\
\hline 1948 & n.a & n.a & n.a & n.a & n.a & 22 & n.a & n.a & $\mathrm{n} . \mathrm{a}$ & n.a & n.a \\
\hline 1974 & 182 & 80 & 12 & 136 & n.a & 11 & 65 & 23 & 4 & 1 & 591 \\
\hline 1976 & 199 & n.a & 13 & n.a & 63 & 18 & 64 & n.a & 45 & 0 & n.a \\
\hline 1980 & 182 & 140 & 84 & 233 & 59 & 33 & 60 & 39 & 45 & 1 & 882 \\
\hline 1986 & 264 & n.a & n.a & 245 & 66 & 58 & 80 & 43 & 5 & n.a & 839 \\
\hline 1989 & 215 & 731 & 63 & 241 & 91 & 55 & 80 & 40 & 4 & 3 & 1598 \\
\hline 1992 & 241 & 115 & 63 & 241 & 91 & 55 & 80 & 41 & 4 & 32 & 1039 \\
\hline 1995 & 241 & 115 & 70 & 241 & 91 & 55 & 67 & 42 & 3 & 32 & 1032 \\
\hline 1998 & 247 & 115 & 75 & 225 & 90 & 55 & 67 & 14 & 2 & 5 & 984 \\
\hline 2000 & 250 & 115 & 84 & 225 & 82 & 50 & 66 & 22 & 2 & 5 & 984 \\
\hline 2004 & 247 & 115 & 92 & 222 & 79 & 49 & 7 & 14 & 0 & 5 & 909 \\
\hline 2007 & 243 & 115 & 56 & 222 & 77 & 48 & 7 & 8 & 0 & 4 & 847 \\
\hline 2009 & 238 & 115 & 59 & 222 & 76 & 30 & 7 & 8 & 0 & 4 & 826 \\
\hline
\end{tabular}

Table 5. Recoverable reserve estimates in Gt as published by the BGR. Year 1980 is seen as identical to the WEC report from the same year. Data source Hö̈k et al. (2010b)

\begin{tabular}{cccccccccccccc}
\hline & USA & China & India & FSU & Australia & $\begin{array}{c}\text { South } \\
\text { Africa }\end{array}$ & Germany & Poland & UK & Indonesia & World \\
\hline $\mathbf{1 9 7 6}$ & n.a & n.a & n.a & n.a & n.a & n.a & n.a & n.a & n.a & n.a & 792 \\
\hline $\mathbf{1 9 8 0}$ & 182 & 140 & 84 & 233 & 59 & 33 & 60 & 39 & 45 & 1 & 882 \\
\hline $\mathbf{1 9 8 8}$ & n.a & n.a & n.a & n.a & n.a & n.a & n.a & n.a & n.a & n.a & 880 \\
\hline $\mathbf{1 9 9 3}$ & 282 & 110 & 62 & 48 & 84 & 68 & 53 & 22 & 3 & 6 & 818 \\
\hline $\mathbf{1 9 9 8}$ & n.a & n.a & n.a & n.a & n.a & n.a & n.a & n.a & n.a & n.a & 806 \\
\hline $\mathbf{2 0 0 1}$ & n.a & n.a & n.a & n.a & n.a & n.a & n.a & n.a & n.a & n.a & 968 \\
\hline $\mathbf{2 0 0 4}$ & 283 & 115 & 125 & 206 & 105 & 49 & 7 & 10 & 0 & 5 & 990 \\
\hline $\mathbf{2 0 0 5}$ & 252 & 115 & 126 & 157 & 107 & 49 & 7 & 10 & 0 & 7 & 935 \\
\hline $\mathbf{2 0 0 6}$ & 247 & 192 & 96 & 204 & 79 & 49 & 41 & 16 & 0 & 7 \\
\hline $\mathbf{2 0 0 7}$ & 263 & 192 & 74 & 215 & 77 & 29 & 41 & 16 & 0 & 7 & 919 \\
\hline $\mathbf{2 0 0 8}$ & 263 & 192 & 81 & 215 & 77 & 31 & 41 & 16 & 0 & 4
\end{tabular}



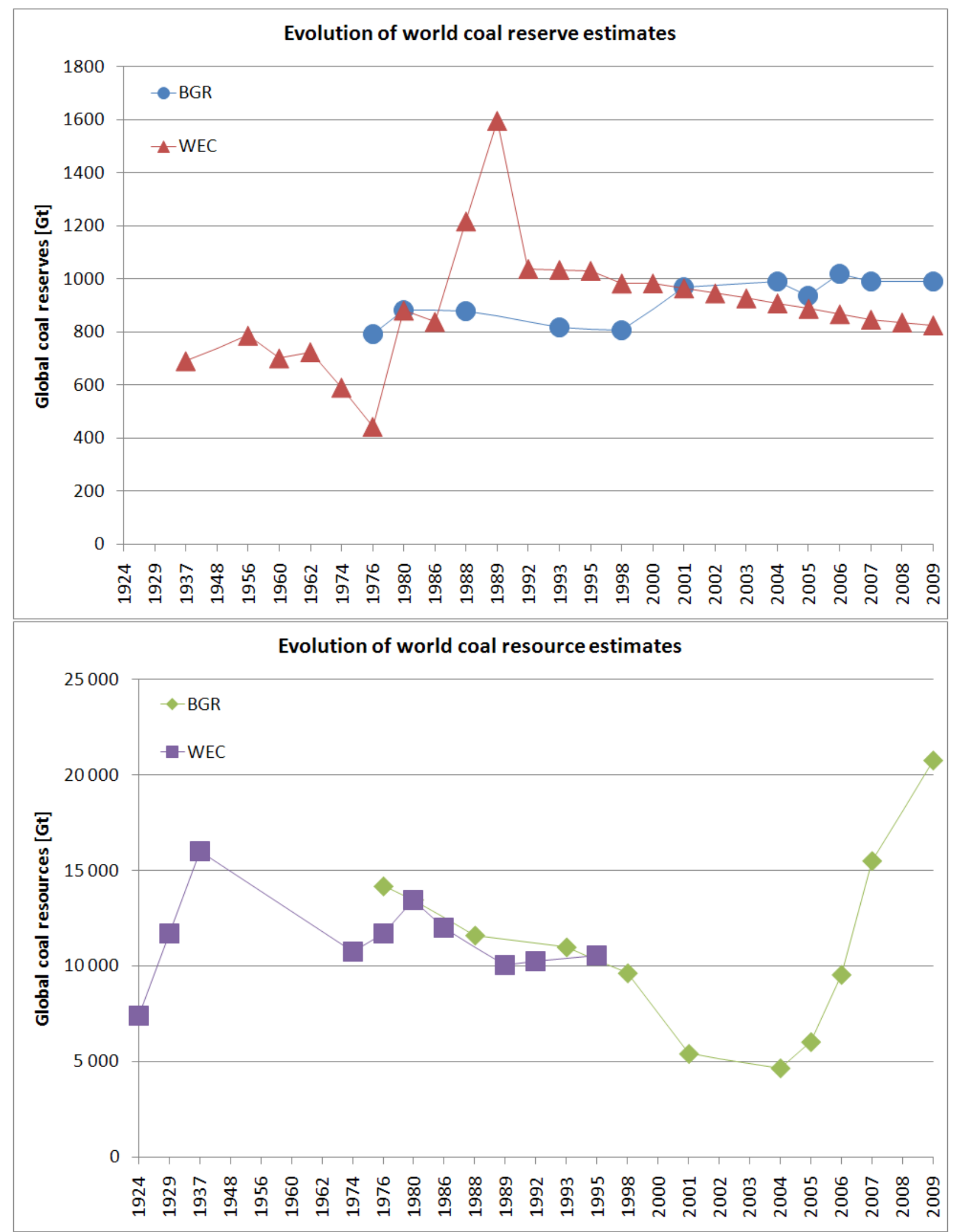

Figure 3. Evolution of the worlds coal reserve and resource estimates made by WEC and BGR since 1924. Adapted from Höök et al. (2010) 


\section{Modelling future production}

All production numbers in SRES (2000) are presented in exajoules (EJ) or zetajoules (ZJ), which are units that are hard to grasp in layman's terms. As a result, we have chosen to convert their figures to more commonly used units. For conversion, we have used 42 GJ as a ton of oil equivalent (toe) and expressed everything in Mtoe or Gtoe.

SRES (2000) assume everything from low to very high resource availability to describe different futures scenarios. The future resource consumption is dependent on future price levels (either assumed as exogenous inputs or determined endogenously in the model) and future technology capable of mining unconventional resources. All the scenario story lines show elements of utopian thinking in particular regarding future technologies capable of decoupling economic growth from energy consumption, how globalization is assumed to even out economic differences and how access to energy is rising in the future (Hjerpe and Linnér, 2008).

Regarding coal, the question is assumed to be only one of economics, accessibility and environmental acceptance. Geological availability and quality issues are simply regarded as noninteresting or solvable with new technology or higher prices. Rogner (1997) stressed the need to have dynamic upper limits and to include both anticipated technology advances and undetermined technological breakthroughs. Simplistic aggregate quantity-cost curves and learning effects are presented as the main articles for modelling energy sources, basically implying that production will "automagically" occur as rising prices makes more and more resources available. However, such an assumption fails to include the complex interaction with other potential energy sources and the fuel demand by society.

Society is dependent on the flows of fossil fuel and the future production is defined through the size of those flows. The size of the tank, i.e. the resource base, is of secondary importance as it is the tap that governs the flow rate and future utilization of fossil fuels in the society. Vast but complicated resources are useless for preventing the coming of a production peak if they cannot be developed fast enough to offset the depletion of "easy" coal. Vast reserve bases have little to do with the likelihood of significant future production, as production is dependent on many more factors than just geological availability. Focusing on future coal reserve levels, while ignoring other factors that affect coal extraction, leads to an incomplete picture for future coal production.

Future coal production will not be entirely determined by what is geologically available, but rather by the fraction of the practically recoverable amounts as well as the demand by consumers. One must remember that society demands energy, not just energy from coal. Hence, if this energy can be obtained less costly and more practically from other energy sources, potentially nuclear power or wind, those will be favored. Increased coal prices do not necessarily lead to increased production, increased reserves, and the transformation of resources into reserves. The price development and feasibility of other energy sources must also be considered, since it is the energy, and not the feedstock that is demanded.

\subsection{A1 family}

This family features rich energy and mineral resources, while rapid technological progress reduces the amount of resources needed for the same level of production and increases the economically recoverable reserves. The A1 family also has some subgroups that explore variants of this rich and technological future. A1C depicts a coal-focused future where new clean coal technologies, such as sulphur removal, have made coal generally environmental-friendly with the 
exception of GHG emissions. A1G describes an oil and gas rich future, with a rapid transition from conventional resources to rich unconventional resources such as methane hydrates. In fact, over 95\% of the total gas resources in Rogner (1997) come from methane hydrates (Höök et al., 2010a). A1T describes a non-fossil future where rapid developments of solar and nuclear technologies replace fossil fuels.

For coal, future production for this scenario family can be found in Figure 4. Massive increases in world production are generally expected and no peak at all is foreseen prior to 2100 in the average case. The A1C-subgroup includes a tenfold increase in world coal production. The other subgroups tend to rely on other energy sources than coal, with massive increases in global oil and gas production as a result (Höök et al. 2010a). Valero and Valero (2010) found that the proven reserves of coal, oil, and natural gas must increase by at least 56\%, 139\% and $288 \%$ to meet the fuel requirements on the A1-subfamily focused on fossil energy (A1F).

In summary, one can only see that this scenario family is optimistic regarding future coal production and has a built-in assumption that no constraints or limitations will apply to coal extraction prior to 2100. A number of scenarios, such as A1 ASF with an oil peak at $182 \mathrm{Mb} / \mathrm{d}$ in 2020 or A1T Maria that phases out coal entirely in the long run, can be ruled out from disagreement with historical data. A number of scenarios shows a peak in coal production around 2050, in agreement with Mohr and Evans (2009) and Höök et al (2010b), but those scenarios also consume unrealistic amounts of oil and gas (Sivertsson, 2004).

Table 3: Cumulative coal production 1990-2100 in the A1 family

\begin{tabular}{|l|c|}
\hline \multicolumn{1}{|c|}{ Scenario name } & Coal [Gtoe] \\
\hline A1 AIM & 379.0 \\
\hline A1 ASF & 1226.9 \\
\hline A1 IMAGE & 533.8 \\
\hline A1 MESSAGE & 451.4 \\
\hline A1 MINICAM & 494.6 \\
\hline A1 MARIA & 201.7 \\
\hline A1C AIM & 1627.3 \\
\hline A1C MESSAGE & 1151.9 \\
\hline A1C MINICAM & 1427.9 \\
\hline A1G AIM & 448.2 \\
\hline A1G MESSAGE & 509.8 \\
\hline A1G MINICAM & 901.4 \\
\hline A1V1 MINICAM & 512.5 \\
\hline A1V2 MINICAM & 540.8 \\
\hline A1T AIM & 294.8 \\
\hline A1T MESSAGE & 277.8 \\
\hline A1T MARIA & 105.0 \\
\hline Al $\boldsymbol{A} \boldsymbol{V} \boldsymbol{E} \boldsymbol{R} \boldsymbol{G} \boldsymbol{G E}$ & 652.1 \\
\hline
\end{tabular}




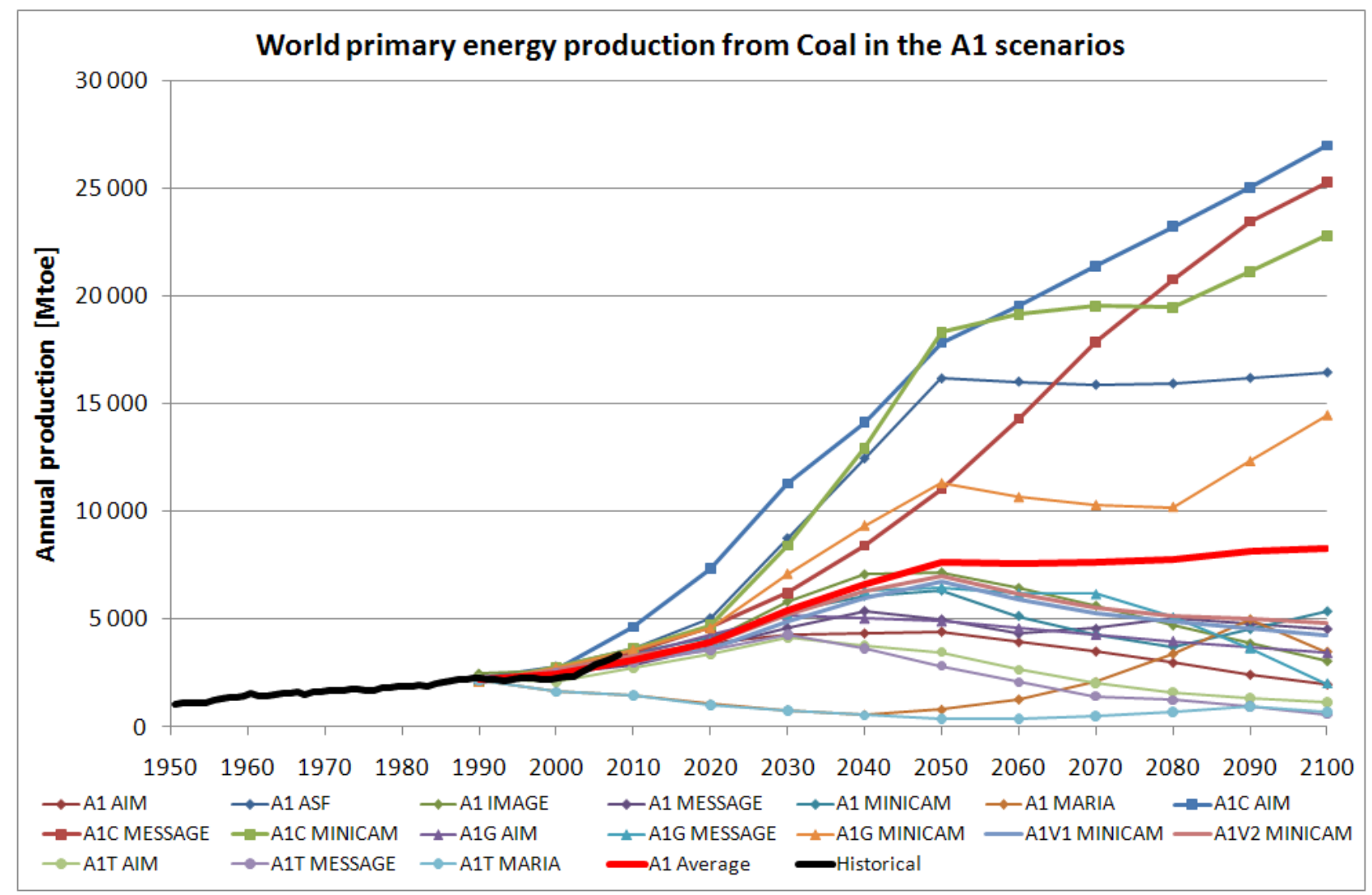

Figure 4. Projected world coal production the in Al scenario family. Production ranges from 800 to nearly 27000 Mtoe by 2100, with an average is 11000 Mtoe without a peak prior to 2100. Adapted from Höök et al. (2010a)

\subsection{A2 family}

This family describes a differentiated world which, compared to A1, is characterized by low trade flows, relatively slow capital stock turnover and slower technological progress. This family also depicts self-reliance in terms of resources and less weight on social, economic and cultural interactions between different regions. A2 is often used as the "business-as-usual" family, where economic development continues without environmental concern or major attempts to reduce the gap between rich and poor countries.

Regions with rich mineral and energy supply will develop into more resource-intensive economies. Other regions with fewer resources will focus on minimizing import dependence and improve efficiency or make use of alternative inputs. The resource availability in different regions mainly determines the fuel mix used. High-income but resource-poor regions develop advanced post-fossil technologies while low-income but resource-rich regions generally rely on older fossil technology. The resource availability is generally rather conservative, and utilization is largely limited to conventional resources without venturing into the field of unconventional fuels, generally resulting in high coal consumption.

Coal will become the dominant fuel since oil production peaks. From being a mere $25 \%$ of the fossil energy in the 2020s, coal grows to over $75 \%$ in 2100 (Valero and Valero, 2010). Coal production is projected with generally continue increasing trends throughout the rest of the century resulting in roughly six times higher coal production by 2100 on average (Figure 5). An exponential increase is more or less the general theme. In addition, Valero and Valero (2010) 
also found that the proven reserves of oil, natural gas and coal would need to increase by $50 \%$, $140 \%$, respectively $89 \%$ in order to meet the projected demand in this scenario family.

The projected outlooks would put enormous pressure on the USA, Russia, China, Australia, India and South Africa as they together hold roughly $90 \%$ of the world's coal reserves and resources (Höök, 2010b). For example, major amounts of the Russian coal are located in the Tunguska and Lena basins in central Siberia (Thomas, 2002), and will not realistically be developed for many decades due to limited infrastructure as well as remoteness and harsh climate.

Since 1860, the cumulative world production of coal has been around 165 Gtoe (Ion, 1974, 1979; Jenkins, 1989; Mitchell, 2003; BP, 2010), with 52 Gtoe alone produced in the last 20 years. With this in mind, the A2 family assumes that the cumulative production by 2100 will be many times the total historical output.

Table 4: Cumulative coal production 1990-2100 in the A2 family.

\begin{tabular}{|l|c|}
\hline \multicolumn{1}{|c|}{ Scenario name } & Coal [Gtoe] \\
\hline A2 ASF & 1113.4 \\
\hline A2 AIM & 1136.6 \\
\hline A2G IMAGE & 514.0 \\
\hline A2 MESSAGE & 747.3 \\
\hline A2 MINICAM & 1117.5 \\
\hline A2-A1 MINICAM & 477.6 \\
\hline A2 Average & 851.1 \\
\hline
\end{tabular}

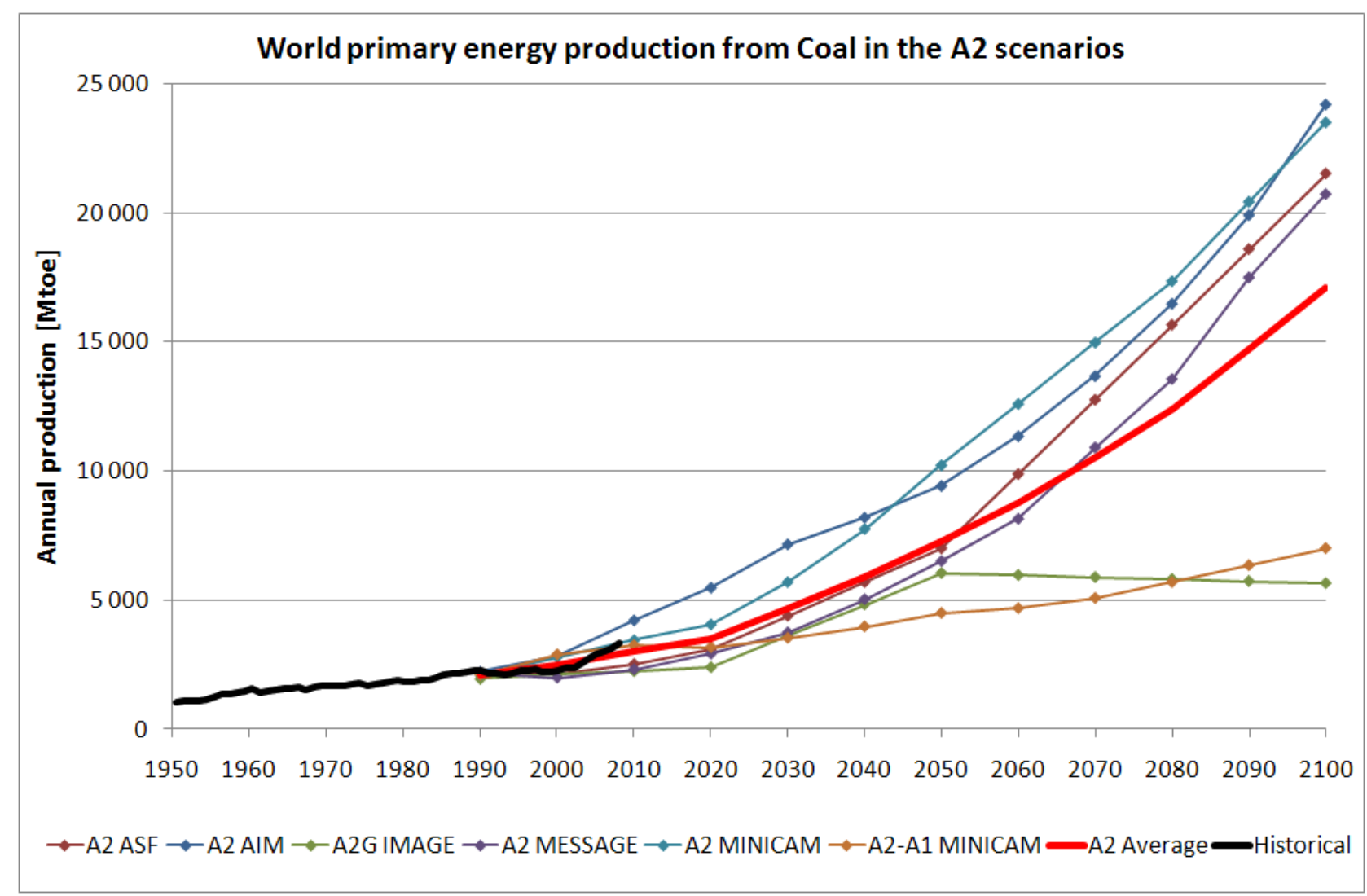

Figure 5. Projected coal production in the A2 family. Adapted from Höök et al. (2010a). 


\subsection{B1 family}

B1 assumed that the capital output ratio of resource exploitation is assumed to rise with increasing depletion, but this is counteracted by learning curve effects. Coal production costs are assumed to rise with increasing depth and rising labour wages but this offset by increased mechanization (for underground mining) and economic scale-up effects.

Coal is significantly lower in the B1 family than in the A1 and A2 families (Figure 6). On average, coal production levels are not dramatically higher than present output. Even though, B1 ASF appears as a rather odd bird with its dramatic deviation from the other scenarios within this family. Other scenarios, such as B1 ASF with an oil production of $170 \mathrm{Mb} / \mathrm{d}$ by 2020 or B1 MARIA that features monotonically decreasing coal production after 1990, can also be ruled out due to poor agreement with actual data.

Valero and Valero (2010) saw that this scenario family depletes around $70 \%$ of the worlds current coal reserves by 2100. Table 5 gives the cumulative production output to 2100 . On average, most of the scenarios reach a maximum production around 2050 (Figure 6). This is in agreement with studies like Mohr and Evans (2009) or Höök et al (2010b).

Table 5: Cumulative coal production 1990-2100 in the B1 family

\begin{tabular}{|l|c|}
\hline \multicolumn{1}{|c|}{ Scenario name } & Coal [Gtoe] \\
\hline B1 IMAGE & 313.9 \\
\hline B1 AIM & 379.8 \\
\hline B1 ASF & 648.6 \\
\hline B1 MESSAGE & 161.2 \\
\hline B1 MARIA & 77.8 \\
\hline B1 MINICAM & 250.1 \\
\hline B1T MESSAGE & 154.1 \\
\hline B1HIGH MESSAGE & 201.6 \\
\hline B1HIGH MINICAM & 305.4 \\
\hline B1 $\boldsymbol{A} \boldsymbol{V E R A G E}$ & 276.9 \\
\hline
\end{tabular}




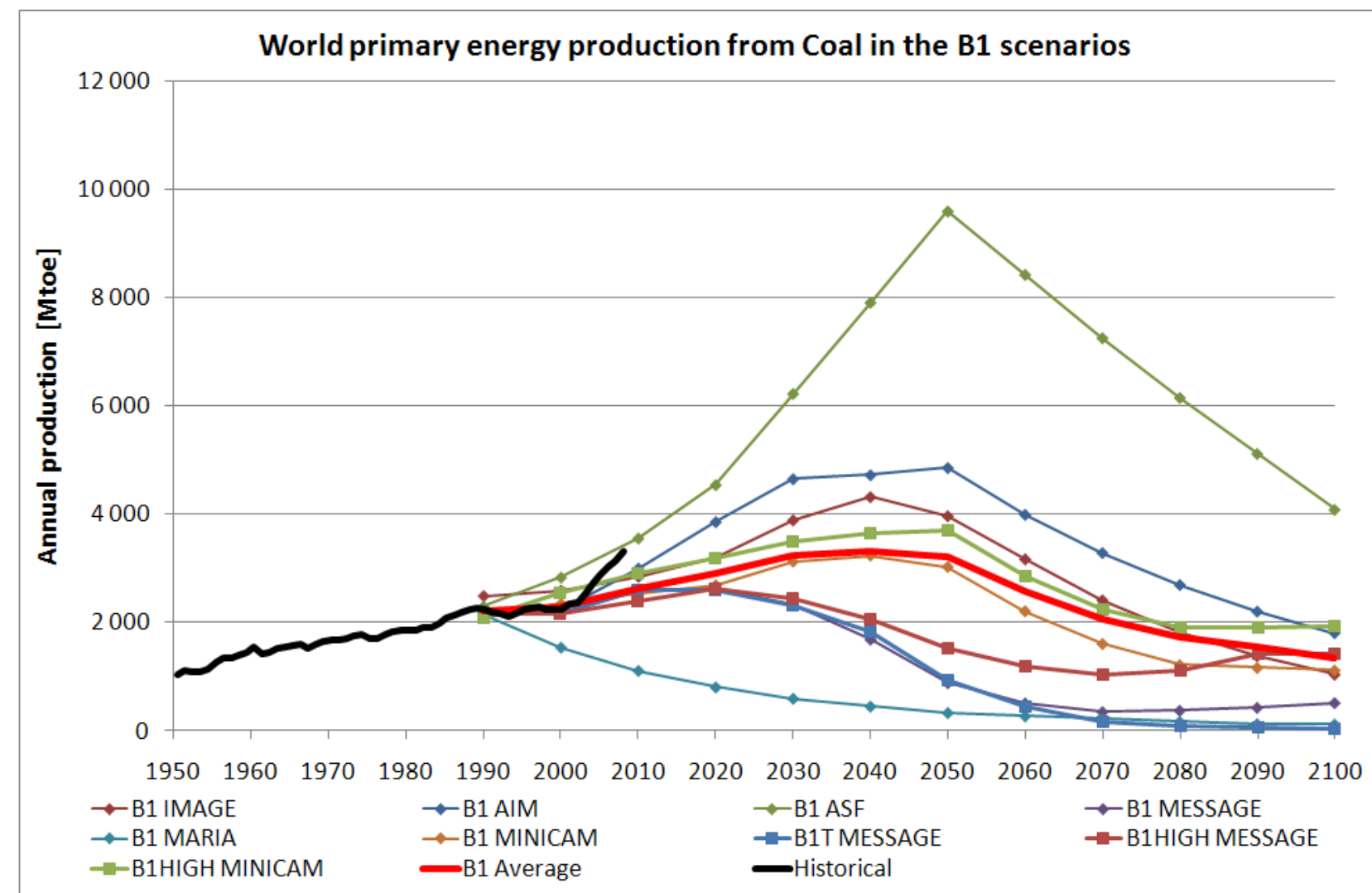

Figure 6. Projected coal production in the B1 scenario family. Adapted from Höök et al. (2010a)

\subsection{B2 family}

Here the available fossil energy is assumed to be conservative. The availability of oil and gas expands only gradually and it not extended much beyond current conventional and unconventional reserves (as of late 1990s). However, coal is assumed to be abundant. Overall this results in relatively limited energy options for the world. Coal production is assumed to be at much higher production levels than present (Figure 7). A tripling of world coal output is the average of this scenario family, while certain individual scenarios can be even more extreme.

Table 6: Cumulative hydrocarbon production 1990-2100 in the B2 family

\begin{tabular}{|l|c|}
\hline \multicolumn{1}{|c|}{ Scenario name } & Coal [Gtoe] \\
\hline B2 MESSAGE & 300.7 \\
\hline B2 AIM & 571.6 \\
\hline B2 ASF & 785.9 \\
\hline B2 IMAGE & 426.9 \\
\hline B2 MARIA & 454.0 \\
\hline B2 MINICAM & 433.7 \\
\hline B2HIGH MINICAM & 1056.1 \\
\hline B2C MARIA & 608.7 \\
\hline B2 $\boldsymbol{A} \boldsymbol{V E R} \boldsymbol{A} \boldsymbol{G E}$ & 579.7 \\
\hline
\end{tabular}




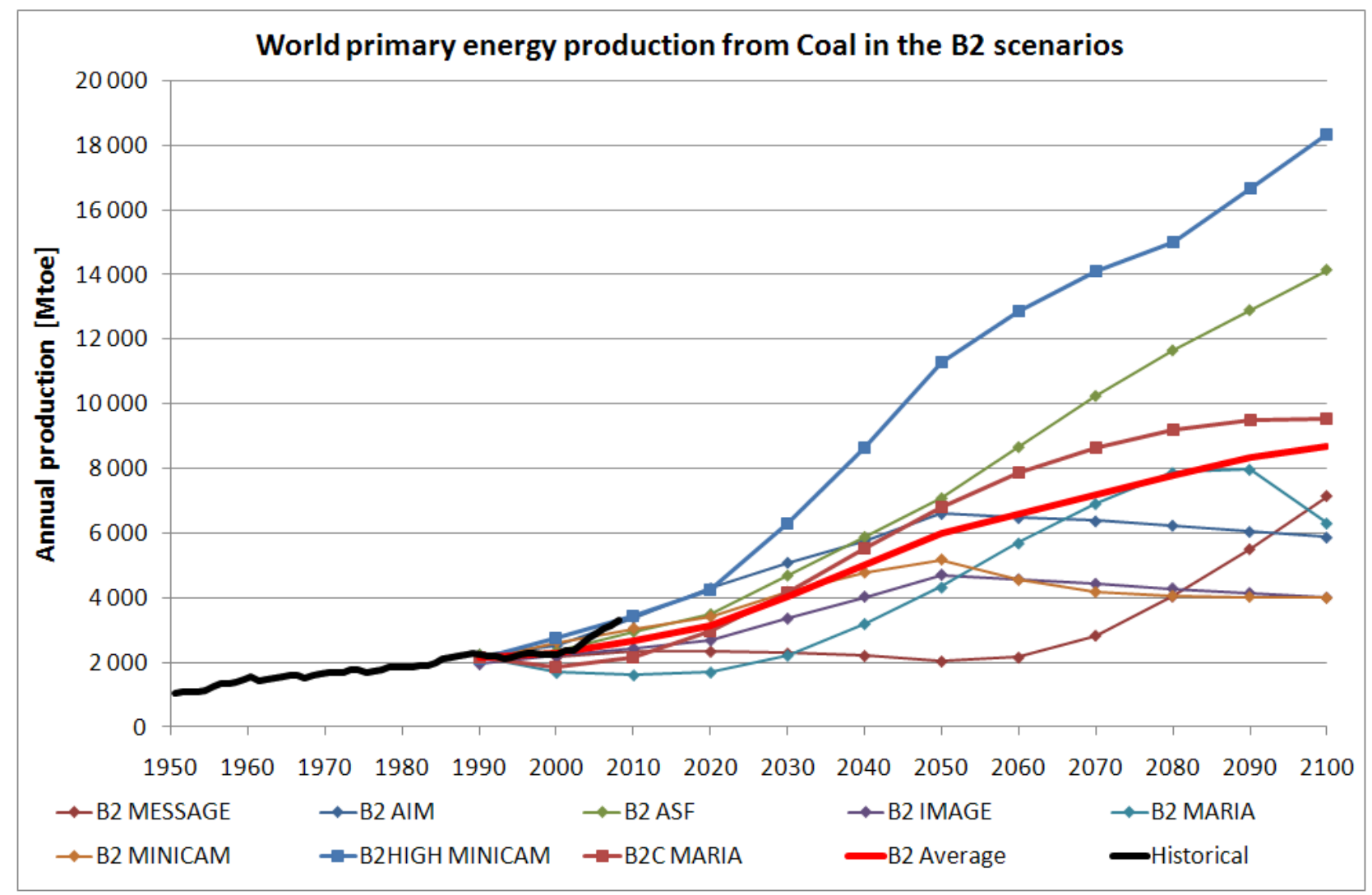

Figure 3: Projected coal production in the B2 scenario family. Adapted from Höök et al. (2010a)

\section{Comments on the SRES production outlooks}

Generally, the most favourable formations have been exploited first while more challenging and/or undesirable formations have been left. In fact, various studies show that depletion can make up for technological progress in the industry (Livernois, 1988; Tilton, 2003; Rodriguez and Arias, 2008; Topp et al., 2008). In essence, the increased costs resulting from the need to mine less favourable formations, i.e. more complex geology, more remote areas, deeper or thinner coal seams, lower quality hydrocarbons and similar, have been matching the cost reductions done by increased mechanization and introduction of new technologies. However, SRES often disregard such information based on little more than optimistic expectations on new technology.

The main message of Rogner (1997) directly shows misunderstanding of the actual problem as well as avoidance of the key question, namely future production. Society is dependent on fossil fuel flows and future production is about the size of those flows. The size of the tank, i.e. the resource base, is of secondary importance as it is the tap that governs the flow rate and future utilization of fossil fuels in the society. Vast unconventional hydrocarbon resources are useless for preventing the coming of a production peak if they cannot be developed fast enough. Once again it must be stressed that vast resources have little to do with the likelihood of significant future production, as production is dependent on many more factors than just geological availability. The important question for society is not the size of reserves. Rather it is the actual flow of energy that can be obtained from the reserves. 
Other peculiar details can also be found in SRES (2000). One of those things is expectations on coal-to-liquids (CTL) technology. CTL technology costs are assumed to be very low, typically below 30 dollars/barrel and even as little as 16 dollar/barrel in some cases (SRES, 2000). Such assumptions seem rather unsound compared to more recent and updated assessments, which ends up around 48-75 US\$/barrel (Vallentin, 2009). The lack of details regarding CTL conversion ratios have been highlighted by Höök and Aleklett (2009). CTL is assumed to be a vital part of future fuel supply in several scenarios. CTL normally yields 1-3 barrels per ton of coal consumed (Höök and Aleklett, 2009).

For example, the world CTL production $(32 \mathrm{Mb} / \mathrm{d})$ by 2100 in the B2 MESSAGE scenario is expected to be higher than the world oil production at the same time. Such a CTLcapacity would alone require more than the present world coal consumption to fuel the synthetic fuel plants, in addition to the amounts needed for "conventional" use of coal in power plants, steel mills and other industries. Can such major expectations on CTL really be made with little more than vague arguments based on technical possibilities?

Patzek and Croft (2010) highlights how 16 of the 40 coal scenarios in SRES simply grow exponentially until the year 2100. Since all scenarios are assigned equal probability, these unreasonable outliers were a weight equal to the more realistic lower scenarios. Patzek and Croft (2010) continues to point out that policy makers tend to focus on the most extreme outcomes, and these outliers have gained severe prominence as inputs to the subsequent climate models. Assigning equal probability to everything ranging from zero coal production to a tenfold increase compared to present levels cannot be a reasonable approach.

In summary, we can only encourage the IPCC to involve more resource experts and natural scientists in future emission scenarios. The current set, SRES (2000), is biased toward exaggerated resource availability and unrealistic expectations on future production outputs.

\section{Conclusions}

Perpetual economic growth is only an extrapolation from history, not a law of nature. Future depletion and the coming of a production peak are both phenomenological observations as well as results derived from physical models. However, perpetual growth is often held as a fundamental assumption for economists and used as a "rule of thumb" for extrapolation. Perpetual growth cannot be used as an underlying assumption for non-renewable energy sources, such as fossil fuels. Rotty (1979) stated that one should be able to make a more accurate analysis than simply projecting continued exponential growth in attempting to estimate the energy demands of the future. Even former technological and economic optimists are now seeing the end of an era with exponential growth (Ayres, 2006). This is hardly surprising, given the underlying arithmetic properties of growth and how quickly unreasonable values are reached for resource production and consumption even for modest growth rates (Bartlett, 1993, 1999, 2004).

SRES is riddled with future production projections that would put unreasonable expectation on just a few countries or regions. Is it reasonable to expect that China, among the world's largest coal reserve and resource holder and producer, would increase their production by a factor of 8 over the next 90 years, as implied by the A1C-scenarios? The concentration of the world's coal reserves and resources to a few countries will result in that a few countries will play the key roles for future production. Many countries will have to rapidly increase their domestic production and consumption by absurdly large factors to fulfil the scenarios presented in SRES. 
Resource-constrained modelling based on mathematical geology and historical time series indicate that most production trajectories in the scenarios are overoptimistic (Rutledge, 2007; Mohr and Evans, 2009; Patzek and Croft, 2010; Höök et al. 2010b). Only the B1 family appears to have any constraints on future coal production compatible with academic studies.

Both Smil (2000) and Bezdek and Wendling (2002) point out that long range energy forecasters have made numerous inaccurate projections, mostly in the form of overestimations. Additionally, many inaccurate forecasts were done in good faith with state-of-the-art models, competent researchers and good funding, showing the difficulty of long-range energy forecasting.

It is argued that many SRES scenarios need to be revised, generally downward, regarding production expectations from coal. Several scenarios also agree poorly with reality over the recent years and some can even be ruled out. SRES is underpinned by a paradigm of perpetual growth and technological optimism as well as old and outdated estimated regarding the availability of coal. As a result, future coal production projections in SRES (2000) are exaggerated and so are the resulting emissions. What kind of repercussions this has on the future climate is an open question which needs to be assessed from several different angles.

\section{Acknowledgements}

I would like to thank Dr Michael Morbius for providing valuable inspiration. Shersti Johansson has my sincerest appreciation for proofreading and commenting.

\section{References}

Ayres, R.U., 2006. Turning point: The end of exponential growth? Technological Forecasting and Social Change, 73(9):1188-1203

Bartlett, A.A., 1993. Arithmetic of growth: methods of calculation. Population and Environment, 14(4):359-387

Bartlett, A.A., 1999. Arithmetic of growth: methods of calculation II. Population and Environment, 20(3):215-246

Bartlett, A.A., 2004. The essential exponential! For the future of our planet. Center for Science, Mathematics and Computer Education, University of Nebraska-Lincoln, $302 \mathrm{p}$

Bezdek, R.H., Wendling, R.M., 2002. A half century of long-range energy forecasts: errors made, lessons learned, and implications for forecasting. Journal of Fusion Energy, 212(34): $155-172$

BGR, 2009. Reserves, resources and availability of energy resources 2009 and previous reports. See also: http://www.bgr.bund.de/

BP, 2010. BP statistical review of world energy 2010. See also: http://www.bp.com

Brecha, R.J., 2008. Emission scenarios in the face of fossil-fuel peaking. Energy Policy, 36(9):34923504

Gregory, K., Rogner, H.H., 1998. Energy resources and conversion technologies for the 21 st century.
Mitigation and Adaptation Strategies for Global Change, 3 (2-4):171-229

Hjerpe, M, Linnér, B.O., 2008. Utopian and dystopian thought in climate change science and policy. Futures, 41(4), 234-245

Höök, M., Aleklett, K., 2010. A review on coal to liquid fuels and its coal consumption. International Journal of Energy Research, article in press

Höök, M., Sivertsson, A., Aleklett, K., 2010a. Validity of the fossil fuel production outlooks in the IPCC Emission Scenarios. Natural Resources Research, 19(2), 63-81

Höök, M., Zittel, W., Schindler, J., Aleklett, K., 2010b. Global coal production outlooks based on a logistic model. Fuel, article in press

IEA, 2009. Key world energy statistics 2009. See also: http://www.iea.org/

Ion, D.C., 1975. Availability of World Energy Resources. Graham \& Trotman Ltd, London, $234 \mathrm{p}$

Ion, D.C., 1979. World energy supplies. Proceedings of the Geologists' Association, 90(4), 193-202

IPCC, 1990. First Assessment Report, see also: http://www.ipcc.ch/ipccreports/assessmentsreports.htm

IPCC, 1995. Second Assessment Report - Climate Change 1995, see also: 
http://www.ipcc.ch/ipccreports/assessmentsreports.htm

IPCC, 2001. Third Assessment Report - Climate Change 2001, see also: http://www.ipcc.ch/ipccreports/assessmentsreports.htm

IPCC, 2007. Fourth Assessment Report - Climate Change 2007, see also: http://www.ipcc.ch/ipccreports/assessmentsreports.htm

Jenkins G, 1989. Oil economists' handbook. Taylor \& Francis Group, London, $484 \mathrm{p}$

Jones, R.N., 2001. An environmental risk assessment/management framework for climate change impact assessments. Natural Hazards, 23(2-3):197-230

Kharecha, P.A., Hansen, J.E., 2008. Implications of "peak oil" for atmospheric CO2 and climate. Global Biogeochemical Cycles, 22(3)

Kontorovich, A.E., 2009. Estimate of global oil resource and the forecast for global oil production in the 21st century. Russian Geology and Geophysics, 50(4):237-242

Livernois, J.R., 1988. Estimates of marginal discovery costs for oil and gas. Canadian Journal of Economics, 21:379-393

Mitchell, B., 2003. International historical statistics 1750-2000. Palgrave MacMillan, London, 2580 $\mathrm{p}$

Mohr, S.H, Evans, G.M., 2009. Forecasting coal production until 2100. Fuel, 88(11):2059-2067

Nel, W.P., Cooper, C.J., 2009. Implications of fossil fuel constraints on economic growth and global warming. Energy Policy, 37(1), 166-180

Patzek, T.D., Croft, G.D., 2010. A global coal production forecast with multi-Hubbert cycle analysis. Energy, 35(8), 3109-3122

Rodríguez, X.A., Arias, C., 2008. The effects of resource depletion on coal mining productivity. Energy Economics, 30(2):397-408

Rogner, H.H., 1997. An assessment of world hydrocarbon resources. Annual Review of Energy and the Environment, 22:217-262

Rotty, R.M., 1979. Growth in global energy demand and contribution of alternative supply systems. Energy, 4(5), 881-890

Rutledge, D., 2007. Hubbert's Peak, the Coal Question, and Climate Change, presentation at the ASPO-USA World Oil Conference, 17-20 October 2007, Houston, Texas, see also: http://rutledge.caltech.edu/

Schenk, N.J., Lensink, S.M., 2007. Communicating uncertainty in the IPCC's greenhouse gas emissions scenarios. Climatic Change, 82(12):293-308

Schneider S, 2001. What is dangerous climate change? Nature, 411, 17-19

Schneider S, 2002. Can we estimate the likelihood of climatic changes at 2100? Climatic Change 52(4), 441-451

Sivertsson, A., 2004. Study of World Oil Resources with a comparison to the IPCC Emissions Scenarios, diploma thesis from Uppsala University 2004, see also: http://www.tsl.uu.se/uhdsg/Publications/Sivertss on Thesis.pdf

Smil, V., 2000. Perils of long-range energy forecasting: reflections on looking far ahead. Technological Forecasting and Social Change, 65(3):251-264.

SRES, 2000. Special Report on Emissions Scenarios, report prepared by the Intergovernmental Panel on Climate Change (IPCC) for the Third Assessment Report. November 2000. See also: http://www.grida.no/publications/other/ipcc_sr/? src=/climate/ipcc/emission/

Thomas, L., 2002. Coal geology, Chichester: John Wiley and Sons, $384 \mathrm{p}$.

Tilton, J.E., 2003. Assessing the threat of mineral depletion. Minerals and Energy, 18:33-42

Topp, V., Soames, L., Parham, D., Bloch, H., 2008. Productivity in the mining industry: measurement and interpretation. Productivity Commission Staff Working Paper, see also: http://www.pc.gov.au/_data/assets/pdf_file/000 5/84911/mining-productivity.pdf

Valero, Al., Valero, A. 2010. A prediction of the exergy loss of the world's mineral reserves in the $21^{\text {st }}$ century. Energy, article in press

Vallentin, D., 2009. Policy drivers and barriers for coal-to-liquids (CTL) technologies in the United States, Energy Policy 2008; 36(8):3198-3211

World Energy Council, 2009. Survey of energy resources interim update 2009 and previous reports. See also: http://www.worldenergy.org/ 